\title{
Use of human embryo lung fibroblasts to detect a heat labile toxin of Escherichia coli from children
}

\author{
HELEN HOLZEL
}

From the Department of Microbiology, Hospital for Sick Children, Great Ormond Street, London WC1, UK

SUMMARY In order to detect the heat labile toxin of Escherichia coli human embryo lung fibroblast cells were seeded with whole cell lysate preparations of the organism to be tested. Positive results consisted of growth inhibition and cytopathic change which were easily seen. Heat-labile toxin was produced by strains belonging to the conventional epidemic serotypes of $E$. coli (EEC) and by non-EEC strains. Toxin-producing organisms were detected in $20 \%$ of healthy children examined. The method is suitable for use in the diagnostic laboratory and is easily adapted to a microtitre plate system suitable for screening purposes.

The association between Escherichia coli and acute diarrhoeal disease of childhood has been known for more than half a century (Adam, 1923). More recently, the lack of correlation between the isolation of specific serological types and the presence of clinical symptoms in children has been documented (Gorbach and Khurana, 1972; Department of Health and Social Security 1972; Rudoy and Nelson, 1975).

Enterotoxin-producing strains of $E$. coli, which seem to bear no particular relation to specified serotypes, have now been identified. Two types of toxin have been described, a low molecular weight heat-stable compound known as ST (Smith and Halls, 1967) and a high molecular weight heat-labile compound, LT (Gyles and Barnum, 1969), which is antigenically related to cholera toxin and similar in its mode of action.

Several investigations of the occurrence of toxinproducing $E$. coli in children have been carried out in different parts of the world, and results of these studies have shown considerable variation. Dean and co-workers (1972) failed to find any strains of $E$. coli that produced the heat-stable toxin, whereas Rudoy and Nelson (1975) demonstrated that $80 \%$ of strains tested produced this compound. Investigations of heat-labile, toxin-producing organisms have shown similar variation. In a retrospective examination of strains of $E$. coli isolated from epidemics of gastro-

Received for publication 17 July 1979 enteritis occurring in the United Kingdom, Gross et al. (1976) failed to find any toxin-producing organisms, whereas in the investigations carried out by Guerrant et al. (1975) $46 \%$ of strains of $E$. coli tested were shown to be capable of producing the heat-labile substance.

At the present time methods available for toxin detection are not suitable for routine use, and this lack of a diagnostic facility has greatly hampered efforts to elucidate the role of toxin-producing $E$. coli in acute diarrhoeal disease of childhood in the United Kingdom.

The following study, carried out at the Hospital for Sick Children, Great Ormond Street (HSC), had three distinct aims: firstly, to evolve a method for detection of heat-labile toxin suitable for routine use in the service laboratory; secondly, to examine heat-labile toxin production by strains of $E$. coli belonging to the traditional infantile enteropathogenic serotypes, EEC, which have caused outbreaks of infantile enteritis in Britain; and, thirdly, to examine heat-labile toxin production by strains of $E$. coli excluding those belonging to the traditional EEC serotypes. These latter strains were isolated from healthy children and were tested to determine the prevalence of toxin-producing $E$. coli in the normal child community.

\section{Material}

CHOLERA TOXIN AND E.COLI TOXIN CONTROL STRAINS

(1) A specific batch of cholera toxin, Burroughs 
Wellcome VT2056B, was used throughout. This was reconstituted in $10 \mathrm{ml}$ Eagle's minimal essential medium (EMEM), which was also used for further dilutions of the material.

(2) Positive control strain E. coli $711 \mathrm{H} 19 \mathrm{~K} 12$ lac Ent positive; negative control strain $E$. coli 711 H 19 K 12 lac Ent negative.

These strains, kindly provided by $\mathrm{Dr} \mathrm{H}$. Williams Smith, were antigenically identical except that the plasmid for heat-labile enterotoxin production had been transferred to the toxin-positive organism from a strain of $E$. coli $026 \mathrm{~K} 60$ isolated from a child with diarrhoea. The two strains had been tested in the isolated ligated rabbit intestinal loop before use and gave the expected result.

\section{TEST STRAINS}

The following test strains were used:

(1) Eight strains of E. coli 0114 isolated during an epidemic of diarrhoeal illness which occurred at the Hospital for Sick Children (HSC) and many other centres during 1969.

(2) Forty-four strains of E. coli reputed to belong to the serotypes included in the $E$. coli polyvalent antisera 2, 3, 4 (Burroughs Wellcome). These strains were recent isolates from an unselected group of children at the Hospital for Sick Children. The patients were (with one exception aged 5 years) less than 3 years of age. Diarrhoeal symptoms were present in $24(55 \%)$ patients and were classified as mild in six $(14 \%)$ in whom no treatment was necessary, moderate in $14(32 \%)$ who were treated by dietary manipulation only, and severe in four $(9 \%)$ in whom intravenous fluid replacement was required.

(3) A strain of E. coli not belonging to the traditional EEC serotypes. This organism was isolated from the duodenal aspirate of a child with severe failure to thrive and possible cow's milk protein intolerance.

(4) Two known toxin-producing strains isolated from adults with severe cholera-like diarrhoea: E. coli strain H 10407, serotype 078 H II from a patient from Bangladesh; and $E$. coli strain $\mathbf{H} 334$ serotype $015 \mathrm{H}$ II from a patient from Calcutta. These strains were provided by $\mathrm{Dr} \mathrm{H}$. Williams Smith.

(5) E. coli strains isolated from healthy children.

Faecal specimens obtained from 15 healthy children under 3 years of age attending a local authority crèche were cultured on MacConkey agar. After overnight incubation at $37^{\circ} \mathrm{C}$ five colonies were selected from each culture and identified as $E$. coli according to the criteria of Cowan (1974). These organisms were tested with $E$. coli polyvalent antisera 2, 3, 4 (Burroughs Wellcome) to exclude the presence of EEC strains.
STORAGE OF E. COLI STRAINS

(a) The strains described in (2), (3) and (5) above were all recent isolates, maintained on nutrient agar slopes at $4^{\circ} \mathrm{C}$ without further subculture. These strains were tested for heat-labile toxin production within four weeks of storage.

(b) Strains from the 1969 E. coli epidemic had been freeze-dried. This method preserves the plasmid for enterotoxin production (Sack, 1976).

(c) The two isolates from adults and the two toxin control strains were stored, as received, on Dorset egg slopes at $4^{\circ} \mathrm{C}$ without subculture. New control strains were supplied by Dr Williams Smith every six months.

\section{HUMAN EMBRYO LUNG FIBROBLAST CELLS} (HEL)

Monolayers of human fetal lung fibroblasts prepared by standard methods were grown in EMEM supplemented with $2 \%$ sodium bicarbonate solution and $10 \%$ fetal calf serum. Cell maintenance medium consisted of EMEM containing $2.5 \%$ sodium bicarbonate and $2 \%$ fetal calf serum. Penicillin/ streptomycin were added to provide a concentration of $200 \mathrm{mg}$ per $\mathrm{ml}$.

\section{Tritiated thymidine $\left(\left({ }^{3} \mathrm{H}\right) \mathrm{T}\right)$}

$\left({ }^{3} \mathrm{H}\right) \mathrm{T}$ aqueous solution containing 5 curies per millimole stock solution was obtained from the Radiochemical Centre, Amersham, Bucks, UK.

\section{Methods}

(1) E. COLI AgGlutination tests

A number of $E$. coli strains referred to the study had been identified as EEC strains on the basis of slide agglutination tests. All strains were therefore verified by tube agglutination tests according to the method recommended by Burroughs Wellcome using appropriate control organisms.

\section{(2) PREPARATION OF E. COLI HEAT-LABILE} TOXIN

Test materials were prepared as whole cell lysates according to the method of Smith and Gyles (1970). Tenfold dilutions of this preparation were made, in EMEM containing $2 \%$ sodium bicarbonate, to give a final volume of $2 \mathrm{ml}$ per dilution. Heat inactivation of the heat-labile toxin (LT) was carried out by boiling the LT preparation for 30 minutes, and further dilutions of the inactivated material were made as above.

(3) HEL FIBROBLAST METHOD FOR HEATLABILE TOXIN DETECTION

A confluent growth of HEL cells was trypsinised and 
resuspended in EMEM to give a cell count of $6 \times 10^{8}$ per $\mathrm{ml}$. Two-millilitre volumes of the cell suspension were added to an equal volume of the LT preparation. The toxin cell suspension was well mixed and pipetted in 1-ml volumes into $6 \times 5 / 8$ in $(152 \times 16 \mathrm{~mm})$ glass tubes. Each dilution was tested in triplicate. Tubes were incubated in the upright position at $37^{\circ} \mathrm{C}$ for $36-42$ hours and were examined by light microscopy for evidence of $(a)$ cell growth inhibition, and $(b)$ cytopathic change. The system was first assesised using cholera VT2056B and LT preparations from the toxin control strains.

Investigations using LT preparations from the test organisms (materials $1,2,3,4,5$ ) were then carried out. The heat-inactivated LT preparation from each strain was tested in parallel. Positive results were recorded when morphological changes were produced by the LT preparation of the test organism and not by the heat-inactivated preparation from the same strain.

TRITIATED THYMIDINE UPTAKE IN TOXINTREATED HEL CELLS

Tritiated thymidine uptake $\left(\left({ }^{3} \mathrm{H}\right) \mathrm{T}\right)$ was measured in HEL cells treated with 10-fold dilutions of LT preparation from the toxin-positive and toxinnegative control strains. Cell-toxin mixtures were incubated for 4 hours with $50 \mu \mathrm{Ci}\left({ }^{3} \mathrm{H}\right) \mathrm{T}$ per $\mathrm{ml}$ of culture. Cells were collected on Whatman glass filters and washed twice with $3 \%$ trichloracetic acid followed by methanol. Counts were made on a beta liquid scintillation counter.

\section{Results}

\section{TUBE AGgLUTINATION TESTS}

Only $26(50 \%)$ of the 52 strains of $E$. coli were shown to belong to the currently recognised EEC strains when examined by tube agglutination tests (Table 1 ). Symptoms were present in $18(69 \%)$ of the children from whom these strains were isolated. Heat-labile toxin preparations from all 52 strains were tested in the HEL system.

\footnotetext{
EFFECT OF CHOLERA AND TOXIN CONTROL STRAINS ON HEL FIBROBLASTS

Addition of cholera toxin to HEL fibroblasts produced cytopathic change consisting of granularity and rounding of cells together with marked growth inhibition. Heat-labile toxin from the positive control strain produced an effect on the fibroblasts identical with that produced by cholera toxin, whereas the addition of the LT preparation from the negative control organism consistently failed to produce these changes (Fig. 1).
}

Table 1 Serological tests of E. coli by slide and tube methods

\begin{tabular}{rlrl}
\hline No. of organisms & \multicolumn{2}{l}{ Results } & \multicolumn{2}{l}{ Tube agglutination } \\
\cline { 2 - 4 } & Slide agglutination & Positive & Negative \\
\cline { 2 - 4 } & & 4 & 1 \\
\hline 5 & 018 & 0 & 2 \\
2 & 026 & 0 & 1 \\
1 & 044 & 2 & 1 \\
3 & 055 & 2 & 1 \\
3 & 086 & 3 & 0 \\
3 & 0111 & 0 & 1 \\
1 & 0112 & 10 & 0 \\
10 & 0114 & 1 & 16 \\
17 & 0125 & 1 & 0 \\
1 & 0126 & 3 & 0 \\
3 & 0127 & 0 & 2 \\
2 & 0128 & 0 & 1 \\
1 & 0142 & 26 & 26 \\
52 & & 0 & 1 \\
\hline
\end{tabular}

Positive = agglutinated to titre of serum; Negative $=$ not agglutinated to titre of serum.

$\left({ }^{3}\right.$ H)T UPTAKE BY TOXIN-TREATED HEL FIBROBLASTS

Treatment of HEL cells with the LT preparation from the negative control strain produced an initial reduction in uptake of tritiated thymidine (Fig. 2). Addition of 10 -fold dilutions of this preparation resulted in a thymidine uptake which increased until a level approaching that by normal fibroblasts was obtained.

Addition of the LT preparation from the toxinpositive control organism produced a decrease in tritiated thymidine uptake which was not removed by dilution of the toxin. The mean values of $\left({ }^{3} \mathrm{H}\right) \mathrm{T}$ uptake by the LT positive treated cells differed significantly from the mean values of $\left({ }^{3} \mathrm{H}\right) \mathrm{T}$ uptake by the LT negative treated cells at all dilutions $(P \ll 0.001)$. This indicates that the morphological changes associated with addition of toxin from the positive control strain were specific toxin effects.

\section{HEAT-LABILE TOXIN DETECTION BY THE HEL METHOD}

Heat-labile, toxin-producing $E$. coli were identified in $12(17 \%)$ of the 70 individuals studied (Table 2$)$.

Four E. coli 0114 strains from the 1969 epidemic produced heat-labile toxin. Three of the patients from whom these strains were isolated had diarrhoea, but the fourth, a 3-month-old boy admitted to hospital with acute epiglottitis and treated with ampicillin, was asymptomatic. Two strains provisionally identified as EEC by slide agglutination tests also produced heat-labile toxin. These organisms, which were not confirmed as EEC strains by tube agglutination tests, were both associated with acute diarrhoeal symptoms. The non-EEC strain 


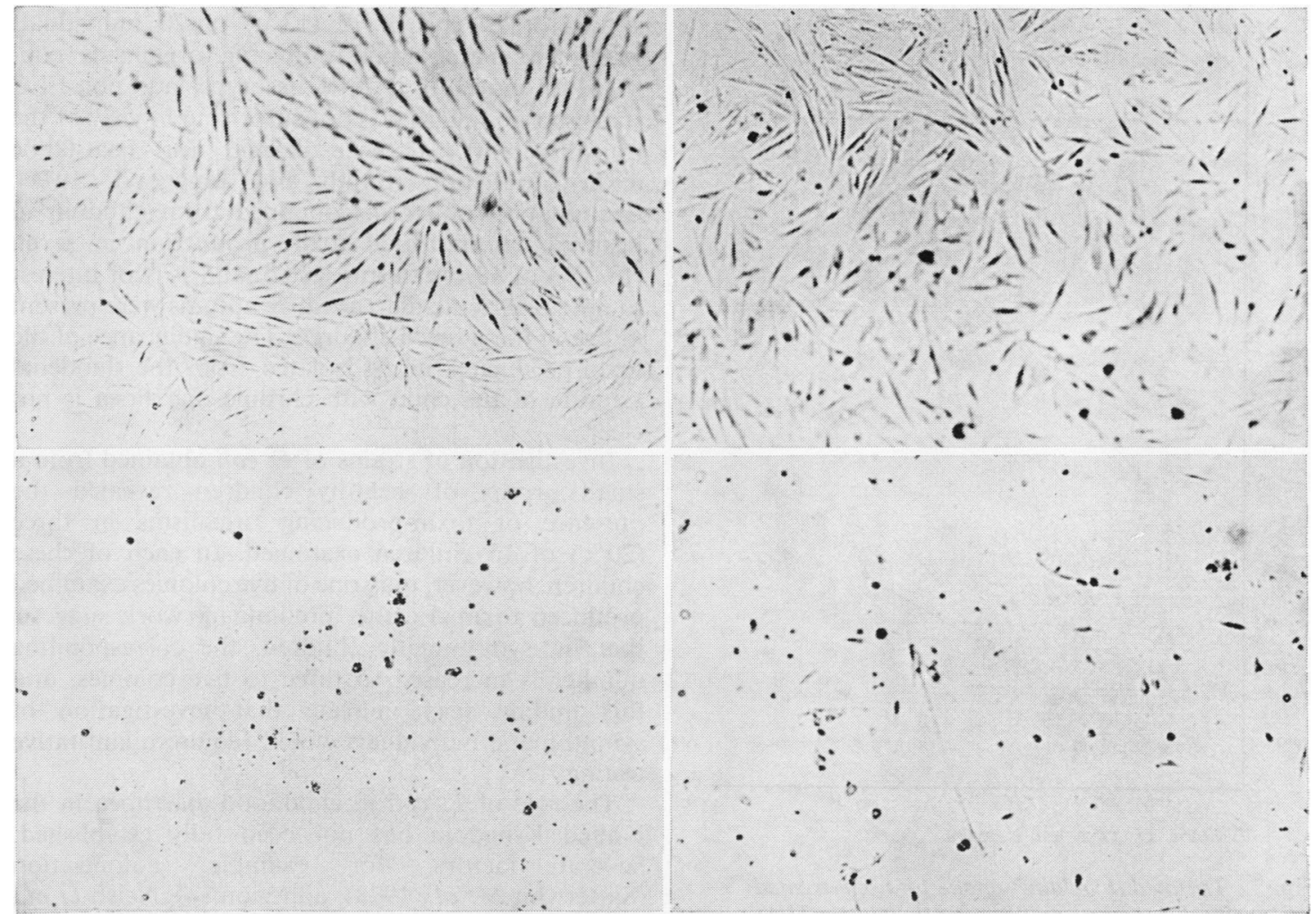

Fig. 1 Human embryo lung fibroblast (HEL) response to cholera toxin and heat-labile toxin preparations (LT) from E. coli control strains. (Upper left) Normal human embryo lung fibroblast. (Lower left) Effect of cholera toxin VT2056B on HEL. (Upper right) Effect of LT preparations from toxin-negative control strains of $\mathrm{E}$. coli. (Lower right) Effect of LT preparations from toxin-positive control strains of E. coli.

from the duodenal aspirate of the child with chronic diarrhoea, and the two known toxin-producing strains isolated from adults, also produced toxin in the HEL system. Toxin-producing strains were also detected in three $(20 \%)$ of the 15 healthy children investigated, although in each of these children only one of five colonies examined was found to produce toxin.

\section{Discussion}

In order to establish the role of toxin-producing $E$. coli in acute diarrhoea of infants and children in this country, further studies are needed, and a system for detecting heat-labile toxin in the diagnostic laboratory is required. When the study began, cell lines of animal origin, ie, Chinese hamster ovary fibroblasts (Guerrant et al., 1974) and Y1 mouse adrenal tumour cells (Kwan and Wishnow, 1974), had undergone limited use for this purpose. These fastidious cultures are not readily available in this country and are unlikely cell lines for routine use. More recently, mouse fibroblasts (Farkas-Himsley and Cheung, 1976) and vero cells (Konowalchuk et al., 1977) have been used to detect heat-labile toxins of $E$. coli, and a wide range of human cell lines have also been investigated for this purpose (Konowalchuk and Spiers, 1979). Human embryo lung fibroblasts, however, are readily acquired in the United Kingdom and are easily maintained. The method of adding the test material with the cells at the time of seeding produces an easily recognised result, consisting of growth inhibition and cytopathic effect. Preliminary experiments demonstrate that these morphological changes are accompanied by activation of adenyl cyclase (Tripp, unpublished observations). A similar result has been obtained in the animal cell lines which respond to heat-labile toxin with cytopathic change (Guerrant et al., 1974). Further preliminary work has shown that this 


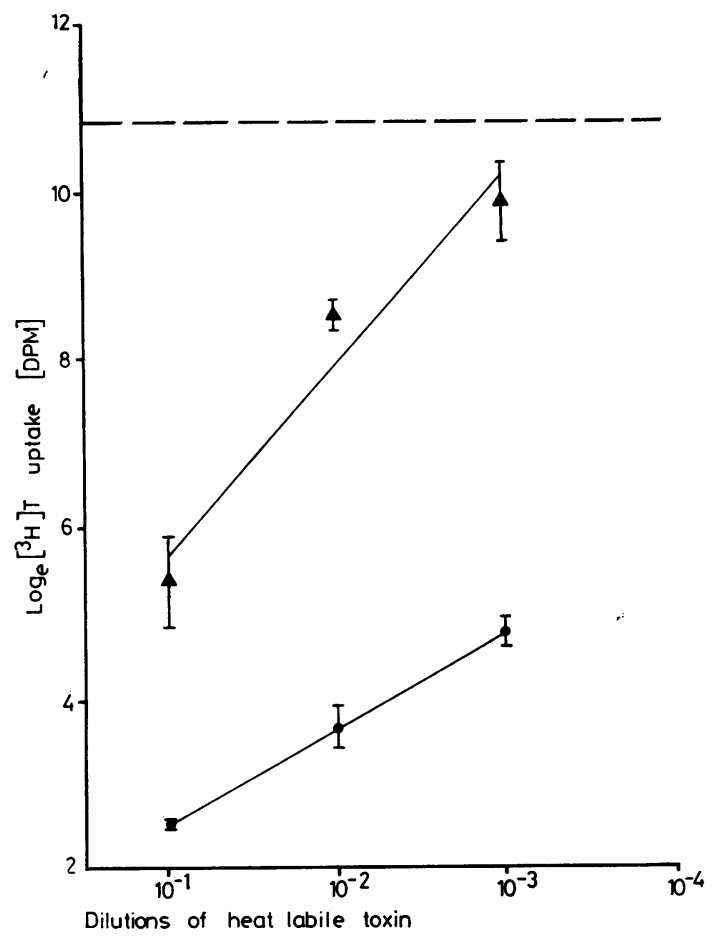

Fig. 2 Tritiated thymidine uptake by toxin-treated HEL cells. Vertical axis: Tritiated thymidine $\left({ }^{3} H\right) T$ counts expressed as disintegrations per minute (DPM). Horizontal axis: Logarithmic dilutions of LT preparations. -- - Uptake by normal HEL cells. - Uptake by cells treated with LT from the toxinnegative control strain. 1 Uptake by cells treated with LT from the toxin-positive control strain. Vertical bars represent \pm one standard error of the mean.

method is easily adapted to a microtitre plate system and as such would be suitable for screening procedures.

Use of the human embryo lung fibroblasts system demonstrated the presence of toxin-producing strains of $E$. coli in $12(17 \%)$ of 70 individuals examined. These toxin-producing organisms consisted of conventional EEC serotypes and non-EEC strains, a finding that is not surprising in view of the transmissibility of the plasmid for heat-labile toxin production (Smith and Linggood, 1971). Examination of strains obtained from children in hospital demonstrated toxin production in seven $(13.2 \%)$ of 53 organisms tested, and it is of interest to note that acute diarrhoeal symptoms were present in five of these seven children. The significance of the toxin-producing strain isolated from the duodenal aspirate of the child with chronic diarrhoea is not clear.

Investigation of strains of $E$. coli obtained from a small group of healthy children revealed the presence of toxin-producing organisms in three $(20 \%)$ of 15 children examined. In each of these children, however, only one of five colonies examined produced toxin. Further preliminary work suggests that, in symptomatic children, the corresponding number is increased to three to five colonies, and this finding may indicate that investigation of symptomatic individuals would require quantitative testing.

The role of $E$. coli in childhood diarrhoea in the United Kingdom has not been fully established. Several factors, for example, colonisation (Satterwhite et al., 1978), adhesion (McNeish et al., 1975), and invasion (Rudoy and Nelson, 1975) in addition to toxin production, are now known to be involved in the pathogenesis of $E$. coli diarrhoea. At the present time these factors are not readily determined in the diagnostic laboratory. The findings of this study indicate that the human embryo lung fibroblast test is a simple and effective method for detecting heat-labile, toxin-producing strains of $E$. coli and may provide a technique useful as part of a routine laboratory procedure in establishing the significance of these organisms in both infantile and adult diarrhoea.

This study was supported by a grant from Action

Table 2 Tests for toxin production on 130 strains of $\mathrm{E}$. coli from 70 individuals

\begin{tabular}{|c|c|c|}
\hline E. coli strains tested & $\begin{array}{l}\text { No. of toxin- } \\
\text { producing organisms }\end{array}$ & Comment \\
\hline 8 epidemic strains of $E$. coli 0114 & 4 & $\begin{array}{l}3 \text { infants with severe diarrhoea } \\
1 \text { infant asymptomatıc }\end{array}$ \\
\hline $\begin{array}{l}44 \text { strains from an unselected group of children at HSC } \\
\text { (24 patients with diarrhoea) }\end{array}$ & 2 & $\begin{array}{l}1 \text { infant with severe diarrhoea } \\
1 \text { infant with moderate diarrhoea } \\
\text { Both were non-EEC strains }\end{array}$ \\
\hline $\begin{array}{l}\text { Non-EEC strain from duodenal aspirate } \\
2 \text { non-EEC strains from adults }\end{array}$ & $\begin{array}{l}1 \\
2\end{array}$ & $\begin{array}{l}\text { Chronic diarrhoea and failure to thrive } \\
\text { Patients with severe cholera-like diarrhoea } \\
\text { Both strains-known toxin producers }\end{array}$ \\
\hline 75 non-EEC strains from 15 well children & 3 & One colony isolated from each of three different children \\
\hline
\end{tabular}


Research for the Crippled Child. I thank Professor J. A. Dudgeon for advice and criticism; Dr D. McSwiggan, Dr W. C. Marshall, Dr M. A. Preece, Dr H. Williams Smith, Mr W. J. Hamilton, and Mr G. Hawkins for their help, and Miss J. Akolatse, Mrs S. Hyder, and Miss C. Tham for secretarial assistance.

\section{References}

Adam, A. (1923). UUber die Biologie der Dyspepsie coli und ihre Beziehungen zur Pathogenese der Dyspepsie und Intoxikation. Jahrbuch für Kinderheilkunde, 101, 295-314.

Cowan, S. T. (1974). Cowan and Steel's Manual for the Identification of Medical Bacteria, 2nd edition. Cambridge University Press, London.

Dean, A. G., Ching, Y. C., Williams, R. G., and Harden, L. B. (1972). Test for Escherichia coli enterotoxin using infant mice: application in a study of diarrhea in children in Honolulu. Journal of Infectious Disease, 125, 407-411.

Department of Health and Social Security (1972). Memorandum on the Ascertainment and Control of Outbreaks of Infantile Gastroenteritis. HMSO, London.

Farkas-Himsley, H., and Cheung, R. (1976). Detection of enterotoxins by a cytotoxic micro-assay. Microbios Letters, 2, 117-123.

Gorbach, S. L., and Khurana, C. M. (1972). Toxigenic Escherichia coli: a cause of infantile diarrhea in Chicago. New England Journal of Medicine, 287, 791-795.

Gross, R. J., Scotland, S. M., and Rowe, B. (1976). Enterotoxin testing of Escherichia coli causing epidemic infantile enteritis in the United Kingdom. Lancet, 1, 629-631.

Guerrant, R. L., Brunton, L. L., Schnaitman, T. C., Rebhun, L. I., and Gilman, A. G. (1974). Cyclic adenosine monophosphate and alteration of Chinese hamster ovary cell morphology: a rapid, sensitive in vitro assay for the enterotoxins of Vibrio cholerae and Escherichia coli. Infection and Immunity, 10, 320-327.

Guerrant, R. L., Moore, R. A., Kirschenfeld, P. M., and Sande, M. A. (1975). Role of toxigenic and invasive bacteria in acute diarrhea of childhood. New England Journal of Medicine, 293, 567-573.

Gyles, C. L., and Barnum, D. A. (1969). A heat-labile enterotoxin from strains of Escherichia coli enteropathogenic for pigs. Journal of Infectious Disease, 120, 419-426.

Konowalchuk, J., and Spiers, J. I. (1979). Response of various cell lines to Escherichia coli toxic products. Canadian Journal of Microbiology, 25, 335-339.

Konowalchuk, J., Spiers, J. I., and Stavric, S. (1977). Vero response to a cytotoxin of Escherichia coli. Infection and Immunity, 18, 775-779.

Kwan, C. N., and Wishnow, R. M. (1974). Escherichia coli enterotoxin-induced steroidogenesis in cultured adrenal tumor cells. Infection and Immunity, 10, 146-151.

McNeish, A., Turner, P., Fleming, J., and Evans, N. (1975). Mucosal adherence of human enteropathogenic Escherichia coli. Lancet, 2, 946-948.

Rudoy, R. C., and Nelson, J. D. (1975). Enteroinvasive and enterotoxigenic Escherichia coli: occurrence in acute diarrhea of infants and children. American Journal of Diseases of Children, 129, 668-672.

Sack, R. B. (1976). Serotyping of E. coli (Letter). Lancet, $1,1132$.

Satterwhite, T. K., Evans, D. G., DuPont, H. L., and Evans, D. J., Jr. (1978). Role of Escherichia coli colonisation factor antigen in acute diarrhoea. Lancet, 2, 181-184.

Smith, H. W., and Gyles, C. L. (1970). The relationship between two apparently different enterotoxins produced by enteropathogenic strains of Escherichia coli of porcine origin. Journal of Medical Microbiology, 3, 387-401.

Smith, H. W., and Halls, S. (1967). Studies on Escherichia coli enterotoxin. Journal of Pathology and Bacteriology, 93, 531-543.

Smith, H. W., and Linggood, M. A. (1971). The transmissible nature of enterotoxin production in a human enteropathogenic strain of Escherichia coli. Journal of Medical Microbiology, 4, 301-305.

Requests for reprints to: Dr Helen Holzel, Public Health Laboratory, Department of Microbiology, Central Middlesex Hospital, Park Royal, London NW10 7NS, UK. 
standard of illustration is high. Every hospital library and every pathologist interested in renal disease will wish to have this book. I forecast that pathologists will have difficulty in preventing clinical colleagues borrowing the laboratory copy. It is unfortunate that the book does not have a more substantial binding for the spine will surely give way with heavy use.

JR TIGHE

Synopsis of Pathology for the Allied Health Professions. AF Gardner. (Pp x + 464 ; \$34.50.) Charles C Thomas. 1979.

There is a continuing need for new books with a fresh approach to the teaching of one or all disciplines of pathology to nurses and to other non-medical health workers. This book covers histopathology only, with a few disastrous excursions into other realms. It is old-fashioned and is marked by errors of principle and of detail. As an example of its unacceptable approach, the chapter on 'Congenital anomalies and hereditary diseases' consists mainly of lists of rarities (with many mistakes) and does not mention 'enzyme'. The book contains no diagrams and has long lists of untitled and undirected pre-1974 references. It cannot be recommended for any reader.

DN BARON

Pathogenic Streptococci. Proceedings of the 7th International Symposium on Streptococci and Streptococcal Diseases, held in September 1978. Ed MT Parker. (Pp 296; illustrated; £21.) Reedbooks Ltd. 1979.

The diminished clinical rôle of Streptococcus pyogenes in developed countries and the continued sensitivity of all isolates to penicillin have distracted the attention of many clinicians and microbiologists from the continuing importance of streptococci as agents of human disease. This handsome volume, which brings together researches carried out in many parts of the world, should help to redress the balance. There is a large section on streptococci of group $\mathrm{A}$, with papers on cellular and extracellular constituents, on pathogenesis, on the immune response to these organisms, on clinical infections and their transmission, and on the specific sequelae, rheumatic fever and glomerulonephritis. There are sections on group B streptococci (long known as pathogens of cattle but only recently recognised as agents of human disease, including meningitis in infants), on pneumococci, on Streptococcus mutans -its rôle in dental caries and the possible control of caries by immunisation-on the streptococci of infective endocarditis, on classification, and on antibiotic resistance, including some interesting papers on resistance transfer. The reasons why streptococci of group A have a relatively small tendency to produce resistant variants, and why their resistance to erythromycin is still rare, though first reported 20 years ago, remain mysterious. The book is packed with information and illustrates the wide range of current studies and ideas on a group of organisms which was discovered 100 years ago.

EJL LOWBURY

Processes in Pathology. An Introduction for Students of Medicine. MJ Taussig. (Pp $\mathrm{x}+456$; illustrated; £6.50.) Blackwell Scientific Publications. 1979.

Teachers of the principles of pathology will greatly enjoy this supposedly 'introductory' textbook of nearly 500 pages. It is well and interestingly written and is lavishly supplied with excellent diagrams However, the few illustrations included are of less value; they are perhaps epitomised by the single electron micrograph which, with its caption, is devoid of any indication of scale.

There are only five sections, and to this extent the scope of the book is limited. The sections concerned with 'Inflammation' and 'Circulation' are clear and succinct and might perhaps be regarded as suitable introductions to pathology for students in medicine. They are, however, unbalanced. For example, in the case of tissue regeneration, several pages are devoted to chalones, while in the case of hypertension, there are several pages concerned with the kallikrein-kinin-prostaglandin system. The question arises whether students of medicine can or should assimilate at an early stage of their career the amount of detailed and at times highly-specialised information provided by this book. Although Taussig certainly appreciates this difficulty when he states that a short book on general pathology is a contradiction in terms, his enthusiasm for new information does seem somewhat incompatible with the requirements of an introductory text.

The three other sections of the book are devoted to 'Immunology', 'Neoplasia', and the 'Genetic Basis of Disease'. These are written at greater length than the rest and should constitute an invaluable introduction to these subjects for research workers entering pathology. They reflect Taussig's special expertise as an immunologist in the Institute of Animal Physiology at Babraham. Unfortunately, however, these sections, like the rest of the book, are accompanied by a bibliography which is cursory and clearly aimed at introductory-course students rather than at those who might wish to verify some of the points made in the text.

Of the more contentious statements, those which refer to regeneration merit comment. There is, for example, the statement that "when muscle tissue is lost through injury, the mass is not regenerated'. Yet skeletal muscle undoubtedly regenerates well after all forms of injury, as workers like Weber, Volkmann, Le Gros Clark, and many others have repeatedly shown throughout the past century. Shortcomings of this kind are not, however, evident in the three more detailed sections, which are excellent.

Taussig clearly envisaged a text that would complement, for example, Florey's General Pathology. He has set his sights too low. We need in this country a detailed Handbook of General Pathology, and three of Taussig's chapters, if expanded to include adequate bibliographies and reviews of the historical and methodological aspects of the subject analysed, would make an important contribution to such a handbook.

JC SLOPER

\section{Correction}

Use of human embryo lung fibroblasts to detect a heat labile toxin of Escherichia coli from children. HELEN HOLzEL ( $J$ Clin Pathol 1979;32:1216).

In Methods (3), line 3, the cell count should read ' $6 \times 10^{4} / \mathrm{ml}$ '. 